\title{
Factors associated with short-term visual improvement after intracorneal ring segments implantation
}

\section{Factores asociados a mejoría visual a corto plazo tras implantación de segmentos intraestromales en pacientes con queratocono}

\author{
Ernesto Soto-Masías ${ }^{1 *}$, Tomas Galvez-Olortegui2,3, Jose Galvez-Olortegui ${ }^{3,4,5,6}$, Fernando Iyo-Alberti ${ }^{7}$ and \\ Gladys Delgado-Becerra ${ }^{1}$ \\ ${ }^{1}$ External Diseases, Cornea and Refractive Surgery Department, Instituto Nacional de Oftalmología Dr. Francisco Contreras Campos, Lima; \\ ${ }^{2}$ Department of Ophthalmology, Hospital Nacional Guillermo Almenara Yrigoyen, Lima; ${ }^{3}$ Evidence-Based Ophthalmology Unit (Ophthalmoevidence), \\ Scientia Clinical and Epidemiological Research Institute, Trujillo; ${ }^{4}$ Vicerrectorado de Investigación, Universidad Nacional Santiago Antúnez de \\ Mayolo, Huaraz; ${ }^{5}$ Executive Directorate for Research and Specialized Teaching in Ophthalmology and Technology Development, Instituto Nacional \\ de Oftalmología, Lima; ${ }^{6}$ Clinical Research Unit, Scientia Clinical and Epidemiological Research Institute, Trujillo; ${ }^{7}$ General Offices Service, Instituto \\ Nacional de Oftalmología Dr. Francisco Contreras Campos, Lima. Peru
}

\begin{abstract}
Objective: To evaluate the correlation between preoperative factors and short-term postoperative visual improvement in patients with keratoconus treated with intracorneal ring segments implantation.Additionally, to determine surgical complications. Methods: Analytical, observational case-control study. One-hundred and ten eyes of 91 patients were included. The preoperative factors evaluated included age,sex,visual acuity,refractive error,surgical technique (mechanical or femtosecond-assisted), pachymetry and keratoconus grade by keratometry. Two groups were obtained according to the gain of lines of uncorrected visual acuity after intrastromal segment implantation surgery, with a gain of 3 or more lines (cases), and a gain of 3 or less lines (controls). Results: Only preoperative myopic astigmatism had a statistically significant higher frequen$c y$ in cases than in controls $(p<0.05)$. Although there was a greater number of eyes with an average keratometry between $4852 D$ (Keratoconus stage II) in the cases group, this was not statistically significant. There was no correlation between the preoperative technique used and the postoperative visual result.The percentage of surgical complications was of $1.81 \%$. Conclusion: The only factor with a statistically significant correlation with uncorrected visual acuity was the previous refractive error. The incidence of postoperative complications was low.
\end{abstract}

Key words: Keratoconus. Intracorneal ring segments. Corneal topography. Corneal ectasia. Keratoconus surgery. Keratoconus therapy.

\section{Resumen}

Objetivo: Determinar la asociación entre factores preoperatorios y la mejoría visual a corto plazo después del implante de segmentos intraestromales en pacientes con queratocono, así como conocer sus complicaciones operatorias. Método: Estudio observacional, analítico de casos y controles. The study included 110 eyes of 91 patients. Los factores preoperatorios

Correspondence:

*Ernesto Soto-Masías

Avenida Tingo María, 398 Cercado de Lima Date of reception: 07-12-2019

C.P. 15082 , Lima, Peru

E-mail: sotomasias@ hotmail.com
Date of acceptance: 17-04-2020

DOI: 10.24875/RMOE.M20000116 (http://creativecommons.org/licenses/by-nc-nd/4.0/).

Available online: 01-07-2020

Rev Mex Oftalmol (Eng). 2020;94(4):142-147

www.rmo.com.mx 
estudiados fueron edad, sexo, agudeza visual preoperatoria, refracción, técnica quirúrgica empleada (mecánica o asistida por femtosegundo), paquimetría y grado de queratocono según queratometría. Se formaron dos grupos según la ganancia de líneas de visión sin correctores después de la cirugía de implante de segmentos intraestromales, con ganancia mayor o igual a tres líneas (casos) y ganancia menor a tres líneas (controles). Resultados: De las variables estudiadas, solo el estado refractivo previo de astigmatismo miópico tuvo una frecuencia mayor estadísticamente significativa $(p<0,05)$ en el grupo de casos que en el de controles. Aunque en el grupo de casos se encontró mayor número de ojos con queratometrías medias entre 48 y $52 D$ (grado II de queratocono), este valor no resultó estadísticamente significativo. No hubo asociación entre la técnica operatoria utilizada y el resultado visual postoperatorio. El porcentaje de complicaciones operatorias fue del 1.81\%. Conclusiones: El estado refractivo previo fue el único factor estudiado con una asociación estadísticamente significativa con la agudeza visual sin correctores postoperatoria. La presencia de complicaciones postoperatorias fue baja.

Palabras clave: Queratocono. Segmentos intraestromales. Topografía corneal. Ectasia corneal. Cirugía de queratocono. Terapia de queratocono.

\section{Introduction}

Keratoconus is a bilateral progressive non-inflammatory degenerative disease that can manifest as a thinning of the corneal stroma; most of the time it is asymmetric, and its etiology is still unknown ${ }^{1}$. The onset of symptoms can occur during adolescence and young adulthood, with reduced vision, corneal astigmatism and fluctuating vision, with a negative impact on the patients quality of life $e^{1,2}$. Currently, the diagnosis has become increasingly frequent with the emergence of refractive surgery and topography that is performed preoperatively to detect any ectatic change, even if it is early ${ }^{3-5}$.

The main objective of the treatment is to improve vision and/or prevent blindness ${ }^{1}$. The type of treatment depends on the severity, as it is initially medical, with eyeglasses or rigid gas permeable contact lenses ${ }^{1}$. When these methods fail, surgery is indicated to improve the corneal surface. When the cornea is transparent, implantation of polymethylmethacrylate (PMMA) intrastromal ring segments can be a successful option ${ }^{6}$.

The objective of this study was to evaluate the possible predictive factors (of the patient or of the surgical technique) of a good uncorrected visual outcome after implantation of intrastromal corneal segments in patients with keratoconus, and to describe the surgical complications.

\section{Materials and methods}

A case-control study was carried out. No sample was calculated and the preoperative clinical records of all keratoconus patients treated with implantation of intrastromal segments were studied at the Instituto Nacional de Oftalmología (INO) Dr. Francisco Contreras Campos in Lima, Peru, during 2018. There were 120 patients that underwent surgery during that period, of which 93 were included in the study since they fulfilled the inclusion criteria based on medical records. Keratoconus was diagnosed by medical specialists from the cornea department, based on clinical examination by biomicroscopy (visualization of signs such as Vogt's striae, Fleischer ring or corneal thinning), refraction (high astigmatism without full correction), keratometry values higher than $47 \mathrm{D}$ and topography with a corneal pachymetry less than 500 um, and increase in anterior and posterior corneal elevations. Participants were divided into two groups (cases and controls) according to the lines gained after at least 3 months of implantation of intrastromal segments. A good gain was considered when it was greater than or equal to 3 lines (cases). Exclusion criteria for both groups were uncorrected preoperative visual acuity (VA) better than 0.3 LogMAR, a corneal ectasia different than keratoconus (pellucid marginal degeneration or ectasia after refractive surgery), implantation of segments of variable thickness, glaucoma, history of corneal cross-linking or other previous eye surgery. Patient records with incomplete data were excluded.

The preoperative factors studied were age, sex, preoperative VA (corrected, uncorrected, and the lines of vision they gained with correction), refraction, surgical technique used (mechanical or femtosecond-assisted), pachymetry, and keratoconus grade according to keratometry. Uncorrected and corrected VA was measured in decimal Snellen notation and converted to the logarithm of the minimum angle of resolution (LogMAR) for statistical analysis. Keratometry and pachymetry variables were obtained from the Galilei G6 topography (Ziemer, Port, Switzerland). For pachymetry, the corneal thinnest point in microns was considered. The keratoconus grading in our study was determined according to the mean keratometry value $(\mathrm{km})$ of the Amsler-Krumeich 
classification: grade I ( $<48 \mathrm{D})$, grade II (48-52 D), grade III (53-55 D) and grade IV (> 55D) ${ }^{7}$. Additionally, intra and postoperative complications were evaluated.

All the implanted segments were made of PMMA, with a $5-\mathrm{mm}$ diameter. One or two segments were placed in each eye, with a thickness ranging from 150 to $300 \mathrm{um}$ (with steps of $50 \mathrm{um}$ ) and arc lengths of $90^{\circ}$, $120^{\circ}, 160^{\circ}$ and $210^{\circ}$. Segments of two different brands were used: Intraseg (Gamma Vision, Buenos Aires, Argentina) were implanted in $94.6 \%$ of the cases and Keraring (Mediphacos, Belo Horizonte, Brazil), in 2.7\%. In $2.7 \%$ of patients, one of each brand was implanted in the same eye.

To estimate the number of segments to be implanted, as well as their length and thickness, the Mediphacos 2009 nomogram was considered. The segments were implanted by expert surgeons. In the manual technique, a diamond cutter was used for the incision, as well as semicircular dissectors for tunneling. In the femtosecond-assisted technique, the laser (Ziemer FEMTO LDV Z8) was used to create the tunnels and the incision. In both, the incision was made in the steepest meridian, and the depth of implantation aimed was at $80 \%$ in the stroma.

Data was analyzed with the SPSS 24 software. Student's t-test, Mann-Whitney $U$ and Chi-square tests were used, and a p-value of less than 0.05 was considered significant. Association was evaluated with the odds ratio $(\mathrm{OR})$ for qualitative variables, and with logistic regression analysis with a 95\% confidence interval for quantitative variables.

This study was approved by the INO Dr. Francisco Contreras Campos Ethics Committee. All the study procedures followed the principles of the Declaration of Helsinki. Informed consent was not requested since a secondary database was used. The data was maintained with confidentiality of the patients who participated in the investigation.

\section{Results}

One-hundred ten eyes (54 cases and 56 controls) of 91 patients were included, of which 67 (73.6\%) were men. Average age was $22.63 \pm 11.27$, with an age range from 6 to 75 years. The characteristics of the patients included in each study group are shown in Table 1. Approximately $50 \%$ of the patients came from the department of Lima, while an important group belonged to Sierra Central (19.8\%).

Within the postoperative results, the average time elapsed since surgery to postoperative monitoring was
Table 1. Clinical-epidemiological characteristics of patients with keratoconus

\begin{tabular}{|l|c|c|}
\hline Characteristic & Cases & Controls \\
\hline Age (mean \pm SD) & $22.13 \pm 10.3$ & $23.11 \pm 12.2$ \\
\hline $\begin{array}{l}\text { Sex, } \mathrm{n}(\%) \\
\text { Male } \\
\text { Female }\end{array}$ & $40(74.1)$ & $42(75)$ \\
\hline $\begin{array}{l}\text { Laterality, } \mathrm{n}(\%) \\
\text { Right eye } \\
\text { Left eye }\end{array}$ & $14(25.9)$ & $14(25)$ \\
\hline
\end{tabular}

of 5.01 months for cases and 4.3 months for controls. Eighty percent of the patients gained at least one line of vision without correction after surgery $(61.8 \%$ gained two or more lines). Also, $10.9 \%$ remained unchanged, and only $8.2 \%$ had a decreased uncorrected vision compared to the preoperative value. There were no differences between the two groups regarding preoperative VA (with and without correction) and the lines gained with correction preoperatively (Table 2).

According to mean keratometry, in the group of cases there was a higher percentage of patients with grade II (mean keratometry between 48 and $52 \mathrm{D}$ ) compared to the control group (Fig. 1), but when evaluating the association between the variables and the post-operative visual outcome by logistic regression analysis, it was found that only the previous refractive state had a statistically significant association with the lines gained (OR: 3.78; 95\% Cl: 1.15-12.45) (Table 3), and a greater number of patients with myopic astigmatism were observed in the group with good visual results compared to the control group (Table 2).

There were no reports of intraoperative complications. In the postoperative period, only two complications occurred (one patient with extrusion 4 months after surgery and the other with displacement of one of the implanted segments after 3 months), both in the control group, representing a complication rate of $1.81 \%$.

\section{Discussion}

The implantation of intrastromal segments produces significant changes in the anterior and posterior curvature radius in the central $3 \mathrm{~mm}$, reducing corneal curvature and irregular astigmatism, thereby improving VA, without significant changes in corneal thickness ${ }^{8}$.

Visual recovery after this surgery can take from 3 to 12 months, so our postoperative evaluation was performed at least the third month after surgery, to have 
Table 2. Study variables by group

\begin{tabular}{|c|c|c|c|c|}
\hline Analyzed factor & Cases & Controls & Total & p \\
\hline Preoperative UCVA (logMAR), median (IOR) & $1.00(0.8-1.3)$ & $0.8(0.7-1.3)$ & $1.0(0.7-1.3)$ & $0.82^{*}$ \\
\hline Preoperative BCVA (logMAR), median (IOR) & $0.5(0.4-0.7)$ & $0.5(0.3-0.7)$ & $0.5(0.3-0.7)$ & $0.77^{*}$ \\
\hline Lines gained with preoperative correction, median (IQR) & $3.0(2.0-6.0)$ & $3.0(2.0-4.5)$ & $3.0(2.0-5.0)$ & $0.15^{*}$ \\
\hline $\begin{array}{l}\text { Keratoconus grade by keratometry, } \mathrm{n}(\%) \\
\text { I and II }(\mathrm{Km}<53 \mathrm{D}) \\
\text { III and IV }(\mathrm{Km} \geq 53 \mathrm{D})\end{array}$ & $\begin{array}{l}35(64.8 \%) \\
19(35.2 \%)\end{array}$ & $\begin{array}{l}30(53.6 \%) \\
26(46.4 \%)\end{array}$ & $\begin{array}{l}65(59.1 \%) \\
45(40.9 \%)\end{array}$ & $0.23^{* *}$ \\
\hline Preoperative pachymetry (microns), mean \pm SD & $434.22 \pm 36.63$ & $441.07 \pm 57.66$ & $437.71 \pm 22.63$ & $0.46^{* * *}$ \\
\hline $\begin{array}{l}\text { Previous refractive error, } \mathrm{n}(\%) \\
\text { Myopic astigmatism } \\
\text { Simple or hyperopic astigmatism }\end{array}$ & $\begin{array}{c}50(92.6 \%) \\
4(7.4 \%)\end{array}$ & $\begin{array}{l}43(76.8 \%) \\
13(23.2 \%)\end{array}$ & $\begin{array}{l}93(84.5 \%) \\
17(15.5 \%)\end{array}$ & $0.02^{* *}$ \\
\hline $\begin{array}{l}\text { Surgical technique, } n(\%) \\
\text { Mechanical } \\
\text { Femtosecond }\end{array}$ & $\begin{array}{l}41(75.9 \%) \\
13(24.1 \%)\end{array}$ & $\begin{array}{l}38(67.9 \%) \\
18(32.1 \%)\end{array}$ & $\begin{array}{l}79(71.8 \%) \\
31(28.2 \%)\end{array}$ & $0.35^{* *}$ \\
\hline
\end{tabular}

Table 3. Analysis of factors associated with visual improvement after implantation of intrastromal segments in patients with keratoconus

\begin{tabular}{|l|c|c|}
\hline Analyzed factor & OR $(95 \%$ CI) & P \\
\hline UCVA PRE & $2.76(0.79-9.70)$ & 0.112 \\
\hline BCVA PRE & $1.14(0.31-4.14)$ & 0.841 \\
\hline Keratoconus grade (I and II) & $0.62(0.29-1.39)$ & 0.23 \\
\hline Pachymetry & $0.99(0.98-1.00)$ & 0.458 \\
\hline Preoperative lines gained & $1.15(0.98-1.36)$ & 0.09 \\
\hline Myopic astigmatism & $3.78(1.15-12.45)$ & 0.029 \\
\hline
\end{tabular}

BCVA PRE: visual acuity with preoperative correction; UCVA PRE: visual acuity without preoperative correction; $95 \% \mathrm{Cl}$ : $95 \%$ confidence interval; OR: odds ratio.

certain stability in the outcomes. The selection criteria must be rigorous and include a severe reduction in VA, clear central corneas with a minimum central thickness of $400 \mathrm{um}$, and a lack of functional vision with correction or contact lenses ${ }^{1}$. There are several nomograms for the selection of the segment to be implanted, based on subjective preoperative refraction, keratometry, topography, and cone location data, and good visual and refractive results of lines gained without correction have been reported after implantation. However, postoperative refractive surprises are not uncommon in terms of visual gain, so there is no established predictability ${ }^{9-13}$.

The groups studied were homogeneous in terms of age and sex. The largest number of patients that

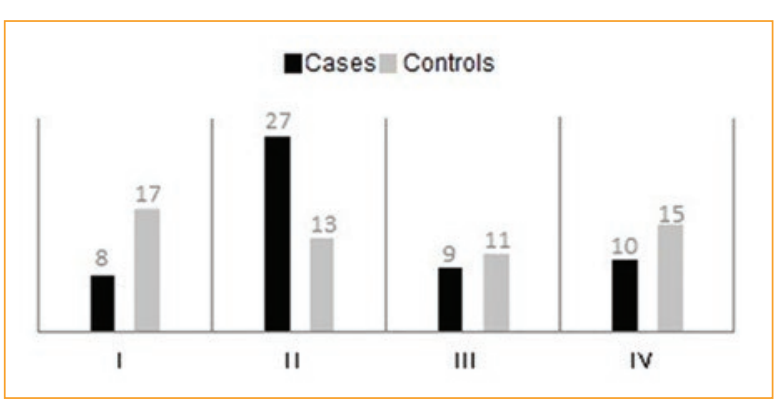

Figure 1. Number of patients in each group according to keratoconus grading.

underwent surgery at the institute came from Lima (approximately $50 \%$ ) and a significant group (37.4\%) from high altitude areas. Some studies indicate that there are differences in the central thickness of the cornea according to the altitude of the region in which they live, being thinner in patients who come from areas over 2,500 meters over the sea level ${ }^{14,15}$. In our study, there could be underreporting of this data, since many patients indicate that they live in the city despite coming from other locations, since they move to the city to receive specific treatment, so this could not be adequately evaluated.

Preoperative VA is a widely studied factor due to its close relationship with visual outcomes after implantation of intrastromal segments. Guyot, et al. found that a best-corrected preoperative VA of 0.3 or better is a prognostic factor for improving at least 2 lines of vision 
with correction after surgery ${ }^{16}$. Peña García, et al. reported that preoperative corrected distance VA on average was better in the group of patients with postoperative visual improvement compared to the group that lost lines of vision after implantation of the segments, observing a greater effectiveness of surgery in patients with a preoperative corrected distance VA from 0.3 to $0.4^{17}$. In a more recent study, Sedaghat, et al. described as a predictor of success a high value of the subtraction between uncorrected and corrected distance VA preoperatively, that is, the greater the gain of preoperative lines of vision with correction, the greater the chance of postoperative success ${ }^{18}$. These results differ from what was observed in our study, where values of uncorrected VA, best-corrected VA and preoperative gain of lines with correction did not have a statistically significant association with a good visual result. This difference could be due to the fact that, in the aforementioned studies, visual success was defined as the gain of 2 lines or more of vision with correction, while in our study, it was defined as the gain of 3 lines or more of vision without correction, making predictability more difficult to establish at this level.

A greater number of eyes had mean keratometry values between 48 to $52 \mathrm{D}$ (grade II), that is, patients with less advanced stages in the cases group; however, a statistically significant difference could not be established for this factor. Alfonso, et al. showed that patients with grades I and II improved their VA after surgery with and without correction, unlike patients with grade III, in whom there was no significant variation in these values $^{19}$. This finding is consistent with our observations, where the final visual outcome was not associated with the keratoconus grade according to keratometry and pachymetry prior to surgery. In contrast, Sedaghat, et al. found no association of preoperative corneal curvature and pachymetry values with postoperative visual success $^{18}$. This difference could be attributed to the fact that in our study there were less patients with advanced keratoconus (> $53 \mathrm{D}$ ) compared to those with a mean keratometry value lower than $53 \mathrm{D}$.

Previous refractive status was the only factor with a statistically significant correlation with good postoperative visual outcomes. In turn, there were more patients with simple or hyperopic astigmatism in the group of those without a good visual outcome. Some studies show a decrease in the magnitude of astigmatism after surgery, such as that of Piñero, et al., who reported that this value decreased from 0.75 to $2.88 \mathrm{D}$, improving corrected and uncorrected postoperative VA, although with a tendency to hypocorrection ${ }^{20}$. Alfonso, et al. showed that in patients with keratoconus grades I and II, there was a significant decrease in astigmatism, which meant that most of them had a significant improvement in postoperative vision with and without correction, in contrast to those with more advanced grades (III), where the change in astigmatism and the improvement of uncorrected VA were minimal ${ }^{19}$. Amanzadeh, et al. reported that segment implantation surgery flattens the cornea and improves its irregularity, reducing the severity of keratoconus, but this is independent of VA changes ${ }^{21}$. In our study, we found a statistically significant association $(p<0.05)$ between preoperative myopic astigmatism and a good postoperative visual outcome compared to the eyes with simple or hyperopic astigmatism. This result is expected considering the action of intracorneal segments that produce a central corneal flattening, thereby reducing the myopic spherical component ${ }^{22}$.

The frequency of reported postoperative complications is of 0.5 to $30 \%$. Among the possible complications we have corneal neovascularization, keratitis, and deposits around the ring segment, halos, pain, corneal edema, photophobia and segment extrusion, which can occur from days to years after implantation $n^{1,23,24}$.

In our study, complications were only reported in two patients, representing a postoperative complication rate of $1.81 \%$, which is within that reported in the medical literature.

Segment insertion can be performed mechanically or assisted with a femtosecond laser. Good visual results have been reported with the mechanical technique, with an acceptable percentage of complications depending on the severity of the pre-existing ectatic condition ${ }^{25}$. The femtosecond laser, on the other hand, reduces complications due to speed, precision, ease of tunnel creation, and centering with a minimal stromal edema, making the corneal ring implantation procedure quicker, easier and safe, with an accurate implantation depth ${ }^{26,27}$. Currently, there are reports of VA improvement with both techniques without statistically significant differences in visual and refractive results ${ }^{28}$. In our study, we found no association between the technique used for the implantation of the intrastromal segments and the postoperative visual outcome. This is consistent with Kubaloglu, et al. and Piñero, et al., who showed similar values of corneal flattening, spherical equivalent decrease and uncorrected VA improvement with both techniques, in addition to similar complication rates ${ }^{28,29}$.

A limitation of our study was the number of subjects, since a greater number of patients, mainly with advanced keratoconus, may modify the association of 
previous mean keratometry with postoperative visual outcomes. Likewise, the results were evaluated at least 3 months after surgery, but the postoperative follow-up time-point was not the same for all patients. In addition, unlike other studies that define postoperative visual success as an improvement of lines of vision with correction, we defined a good visual result as the gain of three or more lines without correction, since we consider that uncorrected vision is the one that has a greater impact on the patient. Although the evidence shows that visual outcomes after this surgery are not very predictable $e^{12}$, this poor predictability may be even greater when evaluating visual improvement without correction.

\section{Conclusions}

Of the factors studied (VA, refraction, pachymetry, keratoconus grade and surgical technique), only previous refractive state was associated with good postoperative visual outcomes without correction. The presence of postoperative complications was low (1.81\%).

\section{Conflicts of interest}

The authors declare no financial interests regarding this work.

\section{Funding}

The authors declare that both the research and the article were self-financed.

\section{Ethical disclosures}

Protection of human and animal subjects. The authors declare that no experiments were performed on humans or animals for this study.

Confidentiality of data. The authors declare that they have followed the protocols of their work center on the publication of patient data.

Right to privacy and informed consent. The authors declare that no patient data appear in this article.

\section{References}

1. Mohammadpour M, Heidari Z, Hashemi H. Updates on Managements for Keratoconus. J Curr Ophthalmol. 2018;30(2):110-24.

2. Israel M, Yousif MO, Osman NA, Nashed M, Abdelfattah NS. Keratoconus correction using a new model of intrastromal corneal ring segments. J Cataract Refract Surg. 2016;42(3):444-54.

3. Blériot A, Martin E, Lebranchu P, Zimmerman K, Libeau L, Weber M, et al. Comparison of 12-month anatomic and functional results between Z6 femtosecond laser-assisted and manual trephination in deep anterior lamellar keratoplasty for advanced keratoconus. J Fr Ophtalmol. 2017; 40(6):e193-200.
4. Wahba SS, Roshdy MM, Fikry RR, Abdellatif MK, Abodarahim AM. Topographic Asymmetry Indices: Correlation between Inferior Minus Superior Value and Index of Height Decentration. J Ophthalmol. 2018;2018:1-4.

5. Shajari M, Jaffary I, Herrmann K, Grunwald C, Steinwender G, Mayer WJ, et al. Early Tomographic Changes in the Eyes of Patients With Keratoconus. J Refract Surg. 2018;34(4):254-9.

6. Arantes JCD, Coscarelli S, Ferrara P, Araújo LPN, Ávila M, Torquetti L. Intrastromal Corneal Ring Segments for Astigmatism Correction after Deep Anterior Lamellar Keratoplasty. J Ophthalmol. 2017; 2017:8689017.

7. Naderan M, Jahanrad A, Balali S. Histopathologic findings of keratoconus corneas underwent penetrating keratoplasty according to topographic measurements and keratoconus severity. Int J Ophthalmol. 2017; 10(11):1640-6.

8. Sedaghat M-R, Momeni-Moghaddam H, Belin MW, Zarei-Ghanavati S, Akbarzadeh R, Sabzi F, et al. Changes in the ABCD Keratoconus Grade After Intracorneal Ring Segment Implantation. Cornea. 2018; 37(11):1431-7.

9. Lyra D, Ribeiro G, Torquetti L, Ferrara P, Machado A, Lyra JM. Computational Models for Optimization of the Intrastromal Corneal Ring Choice in Patients With Keratoconus Using Corneal Tomography Data. J Refract Surg. 2018;34(8):547-50.

10. Utine CA, Ayhan Z, Durmaz Engin C. Effect of intracorneal ring segment implantation on corneal asphericity. Int J Ophthalmol. 2018;11(8):1303-7.

11. Muftuoglu O, Aydin R, Kilic Muftuoglu I. Persistence of the Cone on the Posterior Corneal Surface Affecting Corneal Aberration Changes After Intracorneal Ring Segment Implantation in Patients With Keratoconus. Cornea. 2018;37(3):347-53.

12. Ferrara G, Torquetti L, Ferrara $P$, Merayo-Lloves J. Intrastromal corneal ring segments: visual outcomes from a large case series. Clin Experiment Ophthalmol. 2012;40(5):433-9.

13. Zadnik K, Money S, Lindsley K. Intrastromal corneal ring segments for treating keratoconus. Cochrane Database Syst Rev. 2019; 14;5(5):CD011150.

14. Patyal S, Arora A, Yadav A, Sharma VK. Corneal Thickness in Highlanders. High Alt Med Biol. 2017;18(1):56-60.

15. Liu HM, Bai CH, Liou CM, Chiou HY, Chen C. Central Corneal Thickness of Healthy Lowlanders at High Altitude: A Systematic Review and Meta-Analysis. Curr Eye Res. 2018;43(4):460-5.

16. Guyot C, Libeau L, Vabres B, Weber M, Lebranchu P, Orignac I. Refractive outcome and prognostic factors for success of intracorneal ring segment implantation in keratoconus: A retrospective study of 75 eyes. J Fr Ophtalmol. 2018;42(2):118-26.

17. Peña-García $P$, Vega-Estrada $A$, Barraquer RI, Burguera-Giménez N, Alio JL. Intracorneal ring segment in keratoconus: A model to predict visual changes induced by the surgery. Investig Ophthalmol Vis Sci. 2012:53(13):8447-57.

18. Sedaghat MR, Momeni-Moghaddam H, Piñero DP, Akbarzadeh R, Moshirfar M, Bamdad S, et al. Predictors of Successful Outcome following Intrastromal Corneal Ring Segments Implantation. Curr Eye Res. 2019;44(7):707-15.

19. Alfonso JF, Lisa C, Fernández-Vega L, Madrid-Costa D, Montés-Micó R. Intrastromal corneal ring segment implantation in 219 keratoconic eyes at different stages. Graefe's Arch Clin Exp Ophthalmol. 2011;249(11): 1705-12.

20. Piñero DP, Alió JL, Teus MA, Barraquer RI, Michael R, Jiménez R. Modification and refinement of astigmatism in keratoconic eyes with intrastromal corneal ring segments. J Cataract Refract Surg. 2010;36(9):1562-72.

21. Amanzadeh K, Elham R, Jafarzadepur E. Effects of single-segment Intacs implantation on visual acuity and corneal topographic indices of keratoconus. J Curr Ophthalmol. 2017;29(3):189-93.

22. Söğütlü E, Piñero DP, Kubaloglu A, Alio JL, Cinar Y. Elevation Changes of Central Posterior Corneal Surface After Intracorneal Ring Segment Implantation in Keratoconus. Cornea. 2012;31(4):387-95.

23. Oatts JT, Savar L, Hwang DG. Late extrusion of intrastromal corneal ring segments: A report of two cases. Am J Ophthalmol Case Reports. 2017:8:67-70.

24. Piñero DP, Alio JL. Intracorneal ring segments in ectatic corneal disease - a review. Clin Experiment Ophthalmol. 2010;38(2):154-67.

25. Flecha-Lescún J, Calvo B, Zurita J, Ariza-Gracia MÁ. Template-based methodology for the simulation of intracorneal segment ring implantation in human corneas. Biomech Model Mechanobiol. 2018;17(4):923-38.

26. Mounir A, Radwan G, Mohamed Farouk M, Mohamed Mostafa E. Femtosecond-assisted intracorneal ring segment complications in keratoconus: from novelty to expertise. Clin Ophthalmol. 2018;12(4):957-64.

27. Monteiro T, Alfonso JF, Franqueira N, Faria-Correia F, Ambrósio R, Madrid-Costa D. Predictability of Tunnel Depth for Intrastromal Corneal Ring Segments Implantation Between Manual and Femtosecond Laser Techniques. J Refract Surg. 2018;34(3):188-94.

28. Kubaloglu A, Sari ES, Cinar Y, Cingu K, Koytak A, Coșkun E, et al. Comparison of mechanical and femtosecond laser tunnel creation for intrastromal corneal ring segment implantation in keratoconus: prospective randomized clinical trial. J Cataract Refract Surg. 2010;36(9):1556-61.

29. Piñero DP, Alio JL, El Kady B, Coskunseven E, Morbelli H, Uceda-Montanes A, et al. Refractive and Aberrometric Outcomes of Intracorneal Ring Segments for Keratoconus: Mechanical versus Femtosecond-assisted Procedures. Ophthalmology. 2009;116(9):1675-87. 